\title{
Poor long-term outcome in acute coronary syndrome in a real-life setting: Ten-year outcome of the TACOS study
}

\author{
Kaari K. Konttila ${ }^{1}$, Kimmo Koivula ${ }^{1,2}$, Markku J. Eskola ${ }^{3}$, Mika Martiskainen ${ }^{1}$, \\ Heini Huhtala ${ }^{5}$, Vesa K. Virtanen ${ }^{3}$, Jussi Mikkelsson ${ }^{6}$, Kati Järvelä7, \\ Kari O. Niemelä3, Pekka J. Karhunen ${ }^{1,4}$, Kjell C. Nikus ${ }^{1,3}$ \\ ${ }^{1}$ Faculty of Medicine and Health Technology, Tampere University, Finland \\ ${ }^{2}$ South-Karelia Central Hospital, Finland \\ ${ }^{3}$ Heart Center, Department of Cardiology, Tampere University Hospital, Finland \\ ${ }^{4}$ Fimlab Laboratories Tampere University Hospital, Tampere, Finland \\ ${ }^{5}$ Faculty of Social Sciences, University of Tampere, Finland \\ ${ }^{6}$ Heart Center, Satakunta Central Hospital, Pori, Finland \\ ${ }^{7}$ Heart Center, Tampere University Hospital, Finland
}

\begin{abstract}
Background: Long-term outcome of the three categories of acute coronary syndrome (ACS) in real-life patient cohorts is not well known. The objective of this study was to survey the 10-year outcome of an ACS patient cohort admitted to a university hospital and to explore factors affecting the outcome.

Methods: A total of 1188 consecutive patients (median age 73 years) with ST-elevation myocardial infarction (STEMI), non-ST-elevation myocardial infarction (NSTEMI) or unstable angina pectoris (UA) in 2002-2003 were included and followed up for $\geq 10$ years.

Results: Mortality for STEMI, NSTEMI and UA patients during the follow-up period was $52.5 \%$, $69.9 \%$ and $41.0 \%(p<0.001)$, respectively. In multivariable Cox regression analysis, only age and creatinine level at admission were independently associated with patient outcome in all the three ACS categories when analyzed separately.

Conclusions: All the three ACS categories proved to have high mortality rates during long-term followup in a real-life patient cohort. NSTEMI patients had worse outcome than STEMI and UA patients during the whole follow-up period. Our study results indicate clear differences in the prognostic significance of various demographic and therapeutic parameters within the three ACS categories. (Cardiol J $2021 ; 28,2: 302-311)$
\end{abstract}

Key words: acute coronary syndrome, myocardial infarction, prognosis, unstable angina

\section{Introduction}

Acute coronary syndromes (ACS) represent a spectrum of clinical events ranging from unstable angina pectoris (UA) to non-ST-segment elevation (NSTEMI) and ST-segment elevation myocardial infarction (STEMI). Despite the fact that ischemic heart disease remains the leading cause of death globally [1], data on long-term mortality, especially beyond the first few years, is scarce.

Elderly patients are underrepresented or even excluded in clinical trials. As many as $50 \%$ of realworld acute myocardial infarction (MI) patients may not be represented in randomized clinical tri-

Address for correspondence: Dr. Kjell Nikus, MD, PhD, Heart Center, Department of Cardiology, Tampere University Hospital, Ensitie 4, 33520 Tampere, Finland, tel: +358 505575 396, e-mail: kjell.nikus@sydansairaala.fi

This article is available in open access under Creative Common Attribution-Non-Commercial-No Derivatives 4.0 International (CC BY-NC-ND 4.0) license, allowing to download articles and share them with others as long as they credit the authors and the publisher, but without permission to change them in any way or use them commercially. 
als [2]. On the other hand, the general population is aging, elderly individuals comprise the fastest growing segment of the population worldwide, and coronary artery disease is common in the elderly $[3,4]$. Older MI patients are less likely to receive evidence-based care than younger patients [5].

Studies have shown that UA patients have better short-term outcome than patients with acute MI, but long-term outcome may not differ greatly [6]. According to randomized clinical trials, NSTEMI patients have better outcome than STEMI patients during the first few weeks after the acute event, but they are at higher risk for adverse outcome over the long-term [7].

In a prospective observational study, we previously reported 10-month outcome data of consecutive ACS patients $(n=1188)$ treated in a university hospital [8]. The aim of the present study was to establish the 10-year outcome data of all the three clinical entities of ACS in the same patient cohort. We also studied the effect of baseline clinical factors and data collected during the initial hospital stay on patient outcome.

\section{Methods}

\section{Study population}

Details of the patient selection have been described elsewhere [8]. Briefly, the Tampere Acute COronary Study (TACOS) study cohort consisted of 1188 ACS patients admitted to Tampere University hospital from the city of Tampere and 11 neighboring municipalities, a region of 340,000 inhabitants. From January $1^{\text {st }} 2002$ to March $31^{\text {st }}$ 2003 all patients admitted to the emergency department presenting with acute MI as verified by an elevated blood troponin I (cTnI $>0.2 \mu \mathrm{g} / \mathrm{L}$ ) value were recruited. In addition, from September $1^{\text {st }}$ 2002 to March $31^{\text {st }} 2003$ all consecutive troponinnegative patients with UA were also recruited. Patients who died in or were discharged from the emergency department were not included. The complete study population consisted of 343 (29\%) patients with STEMI, 655 (55\%) with NSTEMI and 190 (16\%) with UA.

The study complies with the Declaration of Helsinki. The Ethics Committee of the Pirkanmaa Hospital District approved the study protocol (Permission R02100). All subjects gave their written informed consent for participation.

\section{ACS categories}

All patients had symptoms and/or clinical signs suggestive of ACS. Patients with STEMI had elevated troponin levels $(>0.2 \mu \mathrm{g} / \mathrm{L})$ and their electrocardiogram (ECG) fulfilled the predefined criteria for STEMI: ST-segment elevation in $\geq 2$ adjacent leads, in leads $V_{1}-V_{6} \geq 1.5 \mathrm{~mm}(\geq 2 \mathrm{~mm}$ in at least one lead), in leads II, III, aVF, and I and $\mathrm{aVL} \geq 1 \mathrm{~mm}$.

Also, in NSTEMI patients, the troponin values were elevated, but the ECG did not fulfil the criteria for STEMI. UA patients showed no elevation in a minimum of two cTnI levels 6-12 h apart.

\section{Follow-up}

Data was collected by a study nurse and two of the investigators (ME and KJN). The follow-up was set to begin at the moment of the ECG recording used for analysis, and it ended at death or at the end of follow-up - March $31^{\text {st }} 2013$. Mortality was gathered by linking the personal identity code from the TACOS study to the Causes of Death register, maintained by Statistics Finland, which records $100 \%$ of deaths of Finnish citizens at home and nearly $100 \%$ abroad. Follow-up was complete with 716 deaths and 472 patients alive at the end of the follow up. When comparing mortality to literature, exact 10 -year mortality was used.

\section{Statistical analysis}

Categorical variables were expressed as numbers of patients or percentages and continuous variables as means or medians followed by quartiles $\left(\mathrm{Q}_{1}-\mathrm{Q}_{3}\right)$. Fisher's exact test was used for categorical variables and the Mann-Whitney $\mathrm{U}$ or Kruskal-Wallis test for numerical variables. A two-tailed $\mathrm{p}$-value of $<0.05$ was considered statistically significant. Kaplan-Meier curves were used to present the unadjusted survival data. Cox regression analysis was used to identify the baseline and in-hospital prognostic variables concerning mortality at follow-up. Cox univariate and multivariable regression analyses including all the variables were presented. Troponin I values were used only for the STEMI and NSTEMI categories due to immeasurable low $(<0.2 \mu \mathrm{g} / \mathrm{L})$ values in UA patients. To utilize the power of the wide study population, the variables previous smoking and coronary angiography were not included in the final model because of lack of data in a significant proportion of patients. Mortality rates at pre-specified points in time were calculated by dividing the amount of cumulative events before the time point by the number of patients at risk at the beginning of the follow-up. All calculations were performed with the SPSS 22.0 statistical package. 


\section{Results}

Baseline characteristics and in-hospital data of the study patients were reported previously [9]. The median age of patients at study inclusion was 73 years (63-80 years) and the male/female ratio was $58 \% / 42 \%$. The NSTEMI patients were older (median age 75 years) than the STEMI (69 years) and UA (68 years) patients. The relative proportion of female patients was higher in the NSTEMI than in the STEMI and UA categories $(46 \%, 36 \%$, and $37 \%$, respectively; $p=0.003$ ). There were no significant differences in the rate of hypertension $(50-55 \%, \mathrm{p}=0.297)$ or diabetes $(22-29 \%$, $\mathrm{p}=0.065$ ) between the three groups. The rate of diuretic usage at admission was highest in the NSTEMI category $(42 \%, 19 \%$, and $32 \%$, respectively; $\mathrm{p}<0.001)$.

The median survival times for the STEMI and NSTEMI categories were 9.7 years and 4.7 years. The mean survival times were 7.3 (95\% confidence interval [CI] 6.8-7.7), 5.4 (95\% CI 5.0-5.7) and 7.7 (95\% CI 7.2-8.3) for STEMI, NSTEMI and UA categories, respectively $(\mathrm{p}<0.001)$. The 5 -year mortality rates were $32.4 \%, 51.3 \%$, and $25.3 \%$ $(\mathrm{p}<0.001)$, while the 10 -year mortality rates were $52.5 \%, 69.9 \%$, and $41.0 \%(\mathrm{p}<0.001)$ for the STEMI, NSTEMI and UA categories, respectively (Fig. 1). Among all deaths, $73.9 \%, 72.5 \%$ and $57.7 \%$ were due to cardiovascular causes for the STEMI, NSTEMI and UA patient categories, respectively $(\mathrm{p}=0.019)$.

Variables predicting outcome at follow-up according to Cox univariate and multivariable regression analyses are presented in Table 1 . Age, male gender, active smoking, diabetes, higher creatinine level, STEMI and NSTEMI ACS categories were independent predictors of worse outcome, while bypass surgery and hypertension were associated with better outcome. Diuretic use both at hospital arrival and discharge was associated with worse outcome, while statin use at discharge was associated with better outcome (Table 2).

When multivariable Cox regression analysis was performed separately for the ACS categories, only age and creatinine level at admission proved to be independent outcome predictors for all three categories (Table 3). Active smoking was an indicator of worse outcome in both STEMI and NSTEMI categories. Diuretic use at discharge had a strong negative impact on outcome both in NSTEMI and UA patients (Table 2). In NSTEMI, which was the largest patient category, invasive treatment and beta-blocker use at discharge were associated with better outcome.

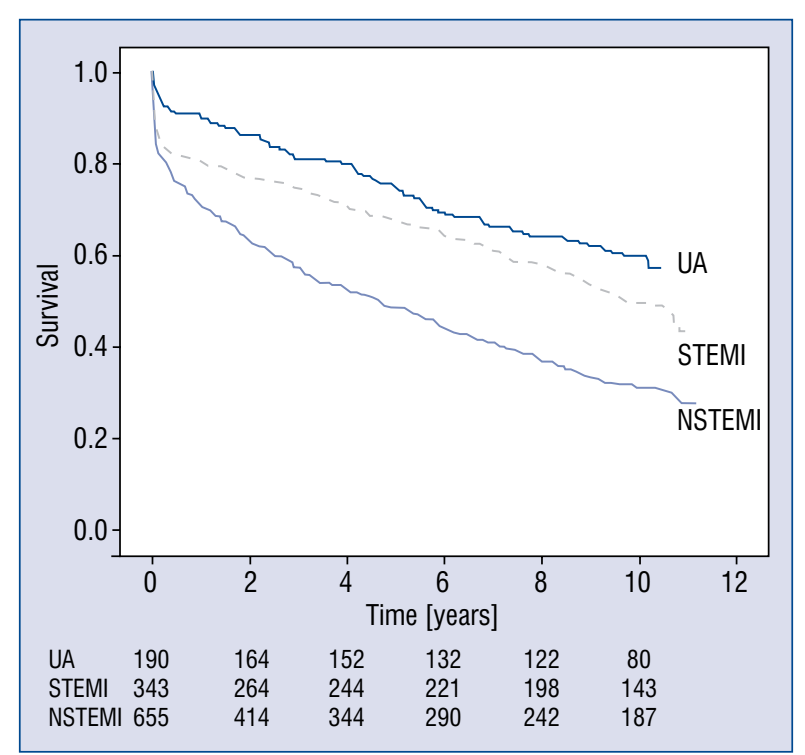

Figure 1. Kaplan-Meier estimates of survival and the number at risk at different time points in the three acute coronary syndrome categories. The $y$ axis shows the proportion of patients alive at different time points $(1.0=100 \%)$; abbreviations - see text.

\section{Discussion}

The present all-comers' study showed that: 1) all 3 patient categories of ACS have poor longterm outcome, 2) NSTEMI patients have the worst outcome, 3) the survival curves of STEMI and NSTEMI patients stay clearly separated for a follow-up period of $\geq 10$ years, 4) UA patients have better outcome than MI patients also in the long term, and 5) factors affecting outcome differ between the three ACS categories.

\section{Randomized clinical trials and the real-life setting in ACS: "Two different worlds"}

In general, there is limited data on patient outcome in ACS beyond the first few years [9]. Especially, there is very little long-term mortality data from complete ACS cohorts, which include STEMI, NSTEMI and UA patients. Existing data shows wide variation in mortality reflecting distinct differences between randomized controlled trials with pre-specified exclusion criteria and "real-life" populations, which include consecutive patients independently of co-morbidities, ethnicity, age and gender. In randomized controlled trials of invasively treated STEMI patients, the 5-year mortality rate in STEMI may be as low as 10\% [10]. The Global Registry of Acute Coronary Events (GRACE) study is widely acknowledged and has had significant im- 


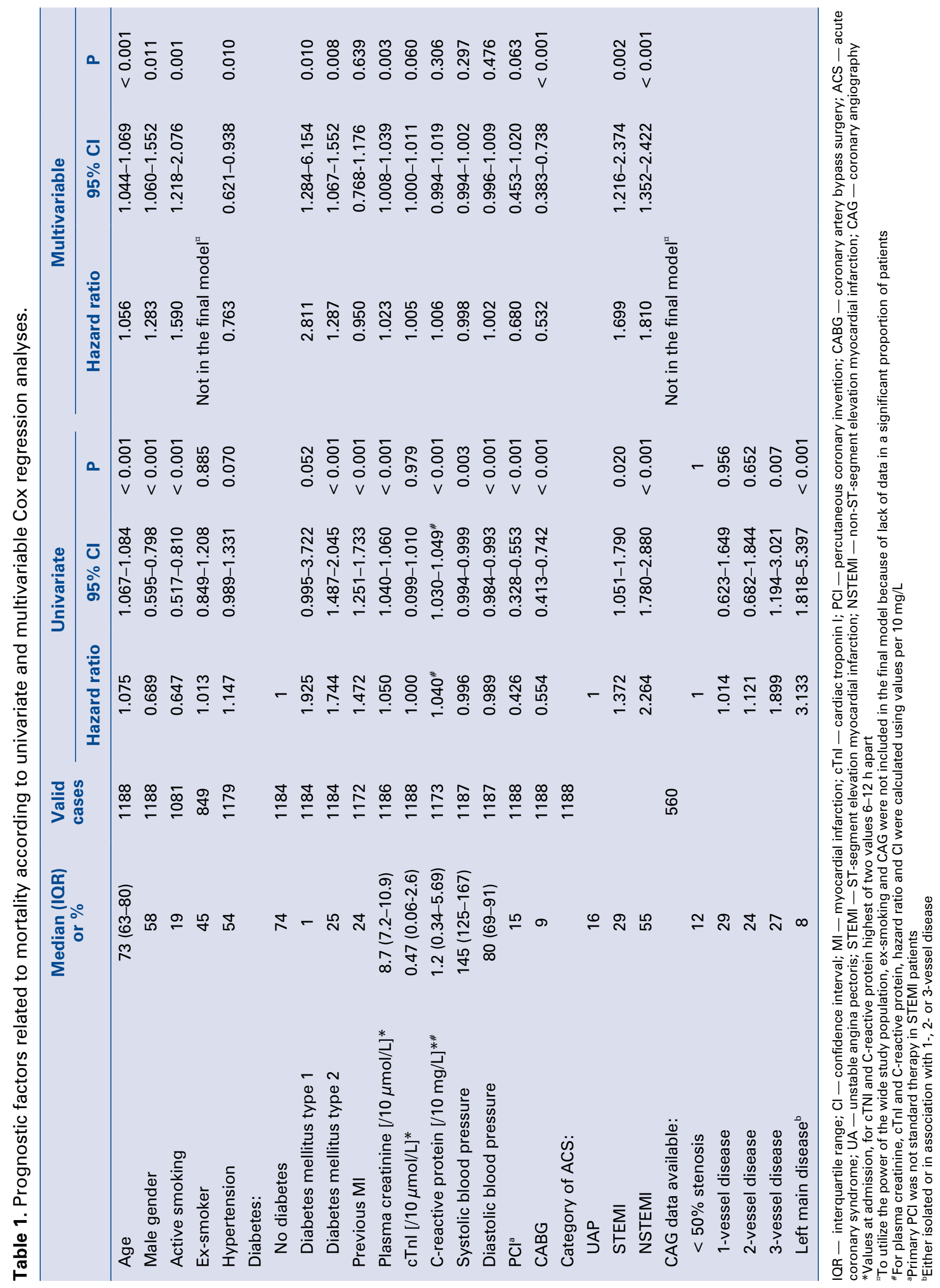


Table 2. Prognostic factors related to mortality according to univariate and multivariable Cox regression analyses

\begin{tabular}{|c|c|c|c|c|c|c|c|c|}
\hline & \multirow{2}{*}{$\begin{array}{c}\text { Median } \\
\text { (IQR) } \\
\text { or } \%\end{array}$} & \multirow{2}{*}{$\begin{array}{l}\text { Valid } \\
\text { cases }\end{array}$} & \multicolumn{3}{|c|}{ Univariate } & \multicolumn{3}{|c|}{ Multivariable } \\
\hline & & & $\begin{array}{c}\text { Hazard } \\
\text { ratio }\end{array}$ & $95 \% \mathrm{Cl}$ & $\mathbf{P}$ & $\begin{array}{c}\text { Hazard } \\
\text { ratio }\end{array}$ & $95 \% \mathrm{Cl}$ & $\mathbf{P}$ \\
\hline \multicolumn{9}{|c|}{ Medication at admission: } \\
\hline ASA & 45 & 1184 & 1.110 & $0.958-1.286$ & 0.165 & 0.968 & $0.785-1.193$ & 0.758 \\
\hline Beta-blocker & 50 & 1186 & 1.283 & $1.108-1.487$ & 0.001 & 1.078 & $0.874-1.329$ & 0.485 \\
\hline Nitrate & 48 & 1186 & 1.603 & $1.383-1.859$ & $<0.001$ & 1.014 & $0.816-1.260$ & 0.900 \\
\hline Calcium-antagonist & 21 & 1186 & 1.228 & $1.032-1.461$ & 0.021 & 1.141 & $0.903-1.442$ & 0.270 \\
\hline Diuretic & 34 & 1186 & 3.161 & $2.721-3.672$ & $<0.001$ & 1.718 & $1.392-2.121$ & $<0.001$ \\
\hline Statin & 22 & 1187 & 0.747 & $0.621-0.900$ & 0.002 & 1.279 & $0.982-1.665$ & 0.068 \\
\hline ACE-inhibitor & 45 & 1185 & 1.520 & $1.286-1.797$ & $<0.001$ & 0.964 & $0.764-1.218$ & 0.761 \\
\hline AT2-inhibitor & 7 & 1186 & 0.963 & $0.720-1.287$ & 0.798 & 1.306 & $0.824-2.071$ & 0.256 \\
\hline Digitalis & 12 & 1187 & 2.566 & $2.112-3.116$ & $<0.001$ & 1.100 & $0.823-1.469$ & 0.520 \\
\hline Warfarin & 45 & 1187 & 2.053 & $1.682-2.505$ & $<0.001$ & 1.004 & $0.714-1.411$ & 0.983 \\
\hline Clopidogrel & 1 & 1186 & 0.370 & $0.139-0.989$ & 0.047 & 0.575 & $0.203-1.627$ & 0.297 \\
\hline \multicolumn{9}{|c|}{ Medication at discharge: } \\
\hline Aspirin & 88 & 1188 & 0.490 & $0.401-0.599$ & $<0.001$ & 0.880 & $0.656-1.180$ & 0.392 \\
\hline Beta-blocker & 93 & 1188 & 0.742 & $0.562-0.979$ & 0.035 & 0.691 & $0.475-1.004$ & 0.053 \\
\hline Nitrate & 72 & 1188 & 1.317 & $1.108-1.564$ & 0.002 & 1.005 & $0.810-1.246$ & 0.967 \\
\hline Calcium-antagonist & 18 & 1188 & 1.160 & $0.966-1.393$ & 0.113 & 0.960 & $0.751-1.226$ & 0.741 \\
\hline Diuretic & 50 & 1188 & 3.273 & $2.751-3.893$ & $<0.001$ & 1.702 & $1.349-2.147$ & $<0.001$ \\
\hline Statin & 34 & 1188 & 0.381 & $0.328-0.442$ & $<0.001$ & 0.710 & $0.573-0.880$ & 0.002 \\
\hline ACE-inhibitor & 47 & 1188 & 1.193 & $1.031-1.382$ & 0.018 & 1.020 & $0.839-1.242$ & 0.841 \\
\hline AT2-inhibitor & 8 & 1188 & 0.906 & $0.683-1.202$ & 0.493 & 0.778 & $0.501-1.208$ & 0.263 \\
\hline Digitalis & 16 & 1188 & 2.515 & $2.110-2.997$ & $<0.001$ & 1.147 & 0.8721 .509 & 0.327 \\
\hline Warfarin & 24 & 1188 & 1.337 & $1.136-1.574$ & $<0.001$ & 1.052 & $0.822-1.345$ & 0.688 \\
\hline Clopidogrel & 20 & 1188 & 0.490 & $0.396-0.605$ & $<0.001$ & 0.927 & $0.661-1.300$ & 0.662 \\
\hline
\end{tabular}

IQR — interquartile range; $\mathrm{Cl}$ — confidence interval; ASA — acetylsalicylic acid; ACE — angiotensin-converting enzyme; AT2 — angiotensin II

pact on risk stratification in ACS [11]. In the "longterm" GRACE study (GRACE UK-Belgian), 5-year mortality of STEMI and NSTEMI patients was $19 \%$ and $22 \%$, respectively [9]. These figures are in strong contrast with the corresponding mortality figures of $32.4 \%$, and $51.3 \%$ in the present study. The 2002 New Zealand ACS Audit Group carried out a comprehensive collection of data from all ACS patients admitted to a New Zealand hospital over a 14-day period in May 2002, and found mortality rates close to those of the present study in STEMI patients $(34 \%)$, while the mortality rate $(33 \%)$ for NSTEMI patients was between that reported in the GRACE UK-Belgian study and the present study [12]. Differences in patient age is probably an important explanatory factor for the observed variation in mortality rates; age at study inclusion was 65/72/69 years for STEMI and 67/73/75 years for NSTEMI in GRACE, New Zealand ACS and TACOS, respectively. Also, a retrospective "real life" analysis of 2,763 consecutive ACS patients found much higher mortality at long-term (median 8.2 years) in patients $>65$ years $(69.7 \%)$ compared with those $\leq 65$ years $(18.6 \%)$ [13].

When comparing longer outcome in STEMI patients, the 10-year mortality rates in the New Zealand ACS audit study (48\%) and the present study (52.5\%) are comparable. In NSTEMI patients, higher 10-year mortality rates were found: $51 \%$ and $69.9 \%$, probably not entirely explained by the 2-year age difference at study inclusion.

A recent meta-analysis of 8 randomized non-ST-segment elevation ACS (NSTE-ACS; NSTEMI and UA together) trials included 6,657 patients [14]. At a mean of 10.3 year follow-up, the risk of all-cause mortality was $28.5 \%$. Again, this is certainly much 
Table 3. Characteristics significant in at least one of the three acute coronary syndrome categories retained in the final multivariate Cox regression model.

\begin{tabular}{|c|c|c|c|}
\hline Characteristic & Hazard ratio & $95 \% \mathrm{Cl}$ & $\mathbf{P}$ \\
\hline \multicolumn{4}{|l|}{ STEMI category } \\
\hline Age & 1.067 & $1.044-1.091$ & $<0.001$ \\
\hline Male gender & 1.141 & $0.744-1.748$ & 0.546 \\
\hline Active smoking & 2.017 & $1.237-3.289$ & 0.005 \\
\hline Hypertension & 0.832 & $0.568-1.220$ & 0.346 \\
\hline \multicolumn{4}{|l|}{ Diabetes: } \\
\hline \multicolumn{4}{|l|}{ No diabetes } \\
\hline Diabetes mellitus type 1 & 7.949 & $1.609-39.264$ & 0.011 \\
\hline Diabetes mellitus type 2 & 1.509 & $1.020-2.233$ & 0.040 \\
\hline Previous MI & 0.658 & $0.413-1.048$ & 0.078 \\
\hline Plasma creatinine $[/ 10 \mu \mathrm{mol} / \mathrm{L}]$ & 1.092 & $1.032-1.155$ & 0.002 \\
\hline C-reactive protein $[/ 10 \mathrm{mg} / \mathrm{L}]$ & 1.029 & $1.004-1.055$ & 0.022 \\
\hline cTnl $[/ 10 \mu \mathrm{mol} / \mathrm{L}]$ & 1.005 & $0.999-1.012$ & 0.114 \\
\hline \multicolumn{4}{|l|}{ Medication at admission: } \\
\hline Diuretic & 1.357 & $0.881-2.089$ & 0.166 \\
\hline ACE-inhibitor & 0.625 & $0.375-1.041$ & 0.071 \\
\hline Warfarin & 0.638 & $0.311-1.307$ & 0.219 \\
\hline PTCA & 0.813 & $0.505-1.309$ & 0.394 \\
\hline CABG & 0.822 & $0.416-1.623$ & 0.572 \\
\hline \multicolumn{4}{|l|}{ Medication at discharge: } \\
\hline Beta-blocker & 0.841 & $0.355-1.994$ & 0.695 \\
\hline Diuretic & 1.137 & $0.768-1.682$ & 0.521 \\
\hline Statin & 0.573 & $0.386-0.853$ & 0.006 \\
\hline Digitalis & 2.111 & $1.136-3.925$ & 0.018 \\
\hline \multicolumn{4}{|l|}{ NSTEMI category } \\
\hline Age & 1.044 & $1.029-1.060$ & $<0.001$ \\
\hline Male gender & 1.121 & $0.892-1.410$ & 0.328 \\
\hline Active smoking & 1.537 & $1.091-2.165$ & 0.014 \\
\hline Hypertension & 0.753 & $0.593-0.955$ & 0.019 \\
\hline \multicolumn{4}{|l|}{ Diabetes: } \\
\hline \multicolumn{4}{|l|}{ No diabetes } \\
\hline Diabetes mellitus type 1 & 1.774 & $0.637-4.939$ & 0.272 \\
\hline Diabetes mellitus type 2 & 1.144 & $0.911-1.436$ & 0.247 \\
\hline Previous MI & 1.066 & $0.842-1.351$ & 0.595 \\
\hline Plasma creatinine $[/ 10 \mu \mathrm{mol} / \mathrm{L}]$ & 1.037 & $1.020-1.055$ & $<0.001$ \\
\hline C-reactive protein $[/ 10 \mathrm{mg} / \mathrm{L}]$ & 0.999 & $0.985-1.013$ & 0.874 \\
\hline $\mathrm{cTnl}[/ 10 \mu \mathrm{mol} / \mathrm{L}]$ & 1.035 & $1.014-1.058$ & 0.001 \\
\hline \multicolumn{4}{|l|}{ Medication at admission: } \\
\hline Diuretic & 1.827 & $1.411-2.366$ & $<0.001$ \\
\hline ACE-inhibitor & 1.104 & $0.864-1.412$ & 0.429 \\
\hline Warfarin & 1.370 & $1.003-1.870$ & 0.048 \\
\hline PTCA & 0.569 & $0.374-0.864$ & 0.008 \\
\hline CABG & 0.456 & $0.310-0.673$ & $<0.001$ \\
\hline \multicolumn{4}{|l|}{ Medication at discharge: } \\
\hline Beta-blocker & 0.554 & $0.352-0.872$ & 0.011 \\
\hline Diuretic & 2.104 & $1.547-2.862$ & $<0.001$ \\
\hline Statin & 0.795 & $0.629-1.005$ & 0.055 \\
\hline Digitalis & 1.250 & $0.951-1.642$ & 0.109 \\
\hline
\end{tabular}


Table 3 (cont.). Characteristics significant in at least one of the three acute coronary syndrome categories retained in the final multivariate Cox regression model.

\begin{tabular}{|c|c|c|c|}
\hline Characteristic & Hazard ratio & $95 \% \mathrm{Cl}$ & $\mathbf{P}$ \\
\hline \multicolumn{4}{|l|}{ UAP category } \\
\hline Age & 1.117 & $1.073-1.164$ & $<0.001$ \\
\hline Male gender & 3.400 & $1.625-7.113$ & 0.001 \\
\hline Active smoking & 1.995 & $0.614-6.481$ & 0.251 \\
\hline Hypertension & 1.003 & $0.558-1.805$ & 0.992 \\
\hline \multicolumn{4}{|l|}{ Diabetes: } \\
\hline \multicolumn{4}{|l|}{ No diabetes } \\
\hline Diabetes mellitus type 1 & 131.881 & $0.882-19712.989$ & 0.056 \\
\hline Diabetes mellitus type 2 & 2.103 & $1.173-3.770$ & 0.013 \\
\hline Previous MI & 0.696 & $0.361-1.345$ & 0.281 \\
\hline Plasma creatinine $[/ 10 \mu \mathrm{mol} / \mathrm{L}]$ & 0.946 & $0.905-0.989$ & 0.015 \\
\hline C-reactive protein [/10 mg/L] & 1.221 & $1.102-1.352$ & $<0.001$ \\
\hline \multicolumn{4}{|l|}{ Medication at admission: } \\
\hline Diuretic & 0.683 & $0.296-1.577$ & 0.372 \\
\hline ACE-inhibitor & 1.354 & $0.704-2.606$ & 0.364 \\
\hline Warfarin & 0.700 & $0.342-1.429$ & 0.327 \\
\hline PTCA & 0.028 & $0.000-4.118$ & 0.160 \\
\hline CABG & 0.222 & $0.047-1.039$ & 0.056 \\
\hline \multicolumn{4}{|l|}{ Medication at discharge: } \\
\hline Beta-blocker & 1.281 & $0.571-2.874$ & 0.548 \\
\hline Diuretic & 4.807 & $1.937-11.931$ & 0.001 \\
\hline Statin & 1.131 & $0.610-2.099$ & 0.695 \\
\hline Digitalis & 0.907 & $0.432-1.900$ & 0.795 \\
\hline
\end{tabular}

ACE - angiotensin-converting enzyme; CABG - coronary artery bypass surgery; $\mathrm{Cl}$ - confidence interval; cTnI — cardiac troponin I; MI — myocardial infarction; NSTEMI - non-ST-segment elevation myocardial infarction; PTCA — percutaneous transluminal coronary angioplasty; STEMI — ST-segment elevation myocardial infarction; UAP — unstable angina pectoris

lower than in both NSTEMI $(69.9 \%)$ and UA (41\%) in the present study. However, the mean age of the NSTE-ACS patients in the meta-analysis was $\sim 76$ at the end of 10.3-year follow-up, while in the present study, the median age at study inclusion in NSTEMI patients was 75 years (68 years for UA) [8].

\section{STEMI/NSTEMI comparison}

Clinical trial evidence is limited with regard to the efficacy and hazards of pharmacological and invasive management of NSTE-ACS in the elderly. According to Alexander et al. [15], the age gap between trials and community populations begins at age 75 and widens with age. Studies have shown that long-term outcome in NSTEMI patients is not improving, and this has been attributed to the fact that they have a more complex phenotype [16]. Compared with STEMI patients, those with NSTEMI tend to be older and have more comorbidity. In the Worcester Heart Attack Study (WHAS) with a population 3,762 patients, post-discharge death rates in a sub-cohort with longer follow-up, 5-year death rates for STEMI (mean age for all patients 65.5 years) and NSTEMI (mean age for all patients 72.6 years) were $30.2 \%$ and $52.4 \%$, which are in the same range as in the present study: $32.4 \%$ for STEMI, 51.3\% for NSTEMI [17].

Regarding STEMI, the introduction of primary percutaneous coronary intervention (PCI) programs and improvements in coronary interventions and medical therapy have resulted in definite improvement in patient outcome $[18,19]$. However, patients $>75$ years of age are underrepresented in randomized clinical STEMI trials; age over 75 or 80 years was a typicalexclusion criteria in many trials [20]. Therefore, limited data is available for guidance on the best management of this growing subset of patients, although registry data seems 
to support the superiority of primary PCI over conservative treatment also in the elderly [21]. The Florence Acute Myocardial Infarction Registry (AMI-Florence) was a population-based prospective observational registry, where the baseline data were collected in 2000-2001 (2002-2003 in our study) [21]. In STEMI patients $(\mathrm{n}=875)$, the 8 -year mortality rate was $49 \%$, comparable to $42.3 \%$ in the present study. In AMI-Florence, primary PCI was performed in $50 \%$ of the STEMI patients admitted within $24 \mathrm{~h}$, whereas in the current study $24 \%$ had PCI during the index hospital admission, while $57 \%$ received fibrinolytic therapy [8].

\section{Unstable angina pectoris}

Existing data on the long-term outcome of UA is scarce mainly due to the fact that researchers tend to combine NSTEMI and UA into NSTE-ACS [22]. It was previously reported that UA patients (median age at study inclusion 68 years) had low in-hospital mortality (2.6\%), but at 10 months, the mortality rate had increased to $12 \%$ [8]. With longer follow-up, 5- and 10-year mortality rates of UA patients clearly increased to $25.3 \%$ and $41 \%$, respectively. The corresponding mortality rate at 10 years in the New Zealand ACS Audit trial was $32 \%$ [12]. In the GRACE UK-Belgian study, 5 -year mortality rate in UA was $18 \%$ [9]. With the introduction of the sensitive troponins to detect myocardial injury, it is probable that a considerable proportion of the UA patients in the present study would be classified as NSTEMI using today's diagnostic methods [23].

\section{Predictors of mortality}

When analyzing all patients together in the present study, the well-established cardiovascular risk factors retained their statistical significance as independent outcome predictors in the multivariable analyses. However, only age and renal dysfunction (higher creatinine levels), which are well documented risk factors, showed negative prognostic impact uniformly in all three ACS categories. For example, active smoking affected outcome only in STEMI and NSTEMI patients, while male gender was associated with inferior outcome only in UA patients. Previous study evidence for a gender difference in mortality in ACS patients is conflicting. In a major systematic review, Buchholz et al. [24] found considerable heterogeneity of study results when analyzing 26 studies reporting mortality at 5 to 9 years. Most studies reported clear attenuation of study results after covariates other than age were introduced in the analyses.
The fact that diuretic use had the strongest impact on the outcome of patients in the NSTEMI category is not surprising, as these patients were older and probably had more co-morbidity, such as heart failure. In the PRAIS-UK registry, which dealt with NSTEMI patients treated in the late 1990's, history of heart failure was a predictor of inferior outcome during 10 -year follow-up [25].

Herein, there is no definite explanation for the protective effect on outcome of hypertension in the NSTEMI patients, other than possible positive effects on use of hypertensive medication on ventricular remodeling. Hypertension could also maintain circulation of the kidneys longer in the severely ill, hypovolemic patients and hence, a delayed progression of kidney failure.

\section{Limitations of the study}

This study has clear limitations; those related to data collection and patient classification were described previously [8]. The follow-up of UA patients was shorter than in the STEMI and NSTEMI groups. The categorization of those with left bundle branch block as NSTEMI or UA patients could increase the risk of random error. However, only $9 \%$ of left bundle branch block patients were treated with fibrinolytic therapy, which supports the decision for this classification.

There are two additional limitations typical for outcome studies with long follow-up in patients with cardiovascular diseases. The first limitation is the low rate of invasive procedures [17]. Especially in STEMI, the rate of invasive procedures during the index hospital stay in the present study was lower than what is typical for Western countries today. Yet, most (55\%) patients in the examined cohort had NSTE-ACS, where the rate of invasive procedures did not increase as much as in the treatment of STEMI [26]. In addition, in the NSTEMI category, the median age at study inclusion was 75 years, and older patients tend to have lower rates of invasive procedures [27]. Also, the use of medical therapy is known to improve outcome, such as statins, were not at the level that is expected in patient care today. Because of these limitations, the study results do not necessarily reflect the outcome of ACS patients treated according to a modern standard. Another general limitation of studies with long-term follow-up is the fact that changes in patient medication and new coronary interventions are difficult or impossible to control for. 


\section{Conclusions}

All three ACS categories herein proved to have high mortality rates during long-term follow-up in a real-life patient cohort. NSTEMI patients had worse outcomes than STEMI and UA patients during the whole follow-up period. The present study results also indicates considerable differences in the prognostic significance of various demographic and therapeutic parameters within the three ACS categories.

\section{Acknowledgements}

The study was supported by grants from the Finnish Cultural Foundation, Special Governmental Subsidy, Finska Läkaresällskapet and the Finnish Medical Foundation. The authors wish to express their thanks to the study nurses, Hanna Näppilä, Johanna Muhos and Senior Laboratory Technician Mervi Seppänen.

\section{Conflict of interest: None declared}

\section{References}

1. World Health Oranization. The top 10 causes of death. 2017. http://www.who.int/mediacentre/factsheets/fs310/en/ (accessed 25 Jan 2018).

2. Zeymer U, Senges J. Why do we need prospective registries in patients with acute myocardial infarction? Eur Heart J. 2003; 24(18): 1611-1612, indexed in Pubmed: 14499222.

3. Fach A, Bünger S, Zabrocki R, et al. Comparison of Outcomes of Patients With ST-Segment Elevation Myocardial Infarction Treated by Primary Percutaneous Coronary Intervention Analyzed by Age Groups ( $<75,75$ to 85 , and $>85$ Years); (Results from the Bremen STEMI Registry). Am J Cardiol. 2015; 116(12): 1802-1809, doi: 10.1016/j.amjcard.2015.09.022, indexed in Pubmed: 26602071.

4. Bromage DI, Jones DA, Rathod KS, et al. Outcome of 1051 Octogenarian Patients With ST-Segment Elevation Myocardial Infarction Treated With Primary Percutaneous Coronary Intervention: Observational Cohort From the London Heart Attack Group. J Am Heart Assoc. 2016; 5(6), doi: 10.1161/JAHA.115.003027, indexed in Pubmed: 27353606.

5. Nauta ST, Deckers JW, Akkerhuis KM, et al. Age-dependent care and long-term (20 year) mortality of 14,434 myocardial infarction patients: changes from 1985 to 2008. Int J Cardiol. 2013; 167(3): 693-697, doi: 10.1016/.j.ijcard.2012.03.064, indexed in Pubmed: 22465352.

6. Capewell S, Murphy NF, MacIntyre K, et al. Short-term and long-term outcomes in 133,429 emergency patients admitted with angina or myocardial infarction in Scotland, 1990-2000: population-based cohort study. Heart. 2006; 92(11): 1563-1570, doi: 10.1136/hrt.2005.085399, indexed in Pubmed: 16775090.

7. Cox DA, Stone GW, Grines CL, et al. Comparative early and late outcomes after primary percutaneous coronary intervention in ST-segment elevation and non-ST-segment elevation acute myocardial infarction (from the CADILLAC trial). Am J Cardiol. 2006;
98(3): 331-337, doi: 10.1016/j.amjcard.2006.01.102, indexed in Pubmed: 16860018.

8. Nikus KC, Eskola MJ, Virtanen VK, et al. Mortality of patients with acute coronary syndromes still remains high: a follow-up study of 1188 consecutive patients admitted to a university hospital. Ann Med. 2007; 39(1): 63-71, doi: 10.1080/08037060600997534, indexed in Pubmed: 17364452.

9. Fox KAA, Carruthers KF, Dunbar DR, et al. Underestimated and under-recognized: the late consequences of acute coronary syndrome (GRACE UK-Belgian Study). Eur Heart J. 2010; 31(22): 2755-2764, doi: 10.1093/eurheartj/ehq326, indexed in Pubmed: 20805110.

10. Moscarella E, Spitaleri G, Brugaletta S, et al. Impact of body mass index on 5-year clinical outcomes in patients with ST-segment elevation myocardial infarction after everolimus-eluting or baremetal stent implantation. Am J Cardiol. 2017; 120(9): 1460-1466, doi: 10.1016/j.amjcard.2017.07.040, indexed in Pubmed: 28864322.

11. Fox KAA, Eagle KA, Gore JM, et al. GRACE and GRACE2 Investigators. The Global Registry of Acute Coronary Events, 1999 to 2009--GRACE. Heart. 2010; 96(14): 1095-1101, doi: 10.1136/ hrt.2009.190827, indexed in Pubmed: 20511625.

12. Ellis CJ, Gamble GD, Williams MJA, et al. Regional Cardiac Society NZ ACS Audit Group. All-Cause Mortality Following an Acute Coronary Syndrome: 12-Year Follow-Up of the Comprehensive 2002 New Zealand Acute Coronary Syndrome Audit. Heart Lung Circ. 2019; 28(2): 245-256, doi: 10.1016/j. hlc.2017.10.015, indexed in Pubmed: 29150157.

13. Plakht Y, Shiyovich A, Gilutz H. Predictors of long-term (10-year) mortality postmyocardial infarction: age-related differences. Soroka Acute Myocardial Infarction (SAMI) Project. J Cardiol. 2015; 65(3): 216-223, doi: 10.1016/j.jjcc.2014.06.001, indexed in Pubmed: 24994020.

14. Elgendy IY, Mahmoud AN, Wen X, et al. Meta-Analysis of Randomized Trials of Long-Term All-Cause Mortality in Patients With Non-ST-Elevation Acute Coronary Syndrome Managed With Routine Invasive Versus Selective Invasive Strategies. Am J Cardiol. 2017; 119(4): 560-564, doi: 10.1016/j.amjcard.2016.11.005, indexed in Pubmed: 27939385.

15. Alexander KP, Newby LK, Cannon CP, et al. American Heart Association Council on Clinical Cardiology, Society of Geriatric Cardiology. Acute coronary care in the elderly, part I: NonST-segment-elevation acute coronary syndromes: a scientific statement for healthcare professionals from the American Heart Association Council on Clinical Cardiology: in collaboration with the Society of Geriatric Cardiology. Circulation. 2007; 115(19): 2549-2569, doi: 10.1161/CIRCULATIONAHA.107.182615, indexed in Pubmed: 17502590.

16. Cohen M. Long-term outcomes in high-risk patients with nonST-segment elevation myocardial infarction. J Thromb Thrombolysis. 2016; 41(3): 464-474, doi: 10.1007/s11239-015-1227-1, indexed in Pubmed: 26001907.

17. Darling CE, Fisher KA, McManus DD, et al. Survival after hospital discharge for ST-segment elevation and non-ST-segment elevation acute myocardial infarction: a population-based study. Clin Epidemiol. 2013; 5: 229-236, doi: 10.2147/CLEP.S45646, indexed in Pubmed: 23901296.

18. Radovanovic D, Nallamothu BK, Seifert B, et al. Temporal trends in treatment of ST-elevation myocardial infarction among men and women in Switzerland between 1997 and 2011. Eur Heart J Acute Cardiovasc Care. 2012; 1(3): 183-191, doi: 10.1177/2048872612454021, indexed in Pubmed: 24062906. 
19. Rogers WJ, Frederick PD, Stoehr E, et al. Trends in presenting characteristics and hospital mortality among patients with ST elevation and non-ST elevation myocardial infarction in the National Registry of Myocardial Infarction from 1990 to 2006. Am Heart J. 2008; 156(6): 1026-1034, doi: 10.1016/j.ahj.2008.07.030, indexed in Pubmed: 19032996.

20. Helft G, Georges JL, Mouranche X, et al. Outcomes of primary percutaneous coronary interventions in nonagenarians with acute myocardial infarction. Int J Cardiol. 2015; 192: 24-29, doi: 10.1016/j.ijcard.2015.04.227, indexed in Pubmed: 25985011.

21. Barchielli A, Santoro GM, Balzi D, et al. Long-term prognosis after primary $\mathrm{PCI}$ in unselected patients with ST-elevation myocardial infarction. J Cardiovasc Med (Hagerstown). 2012; 13(12): 819-827, doi: 10.2459/JCM.0b013e328356a29c, indexed in Pubmed: 22772599.

22. Polonski L, Gasior M, Gierlotka M, et al. A comparison of ST elevation versus non-ST elevation myocardial infarction outcomes in a large registry database: are non-ST myocardial infarctions associated with worse long-term prognoses? Int J Cardiol. 2011; 152(1): 70-77, doi: 10.1016/j.ijcard.2010.07.008, indexed in Pubmed: 20684999.

23. Roffi M, Patrono C, Collet JP, et al. 2015 ESC Guidelines for the management of acute coronary syndromes in patients presenting without persistent ST-segment elevation: Task Force for the
Management of Acute Coronary Syndromes in Patients Presenting without Persistent ST-Segment Elevation of the European Society of Cardiology (ESC). Eur Heart J. 2016; 37(3): 267-315, doi: 10.1093/eurheartj/ehv320, indexed in Pubmed: 26320110.

24. Bucholz EM, Butala NM, Rathore SS, et al. Sex differences in long-term mortality after myocardial infarction: a systematic review. Circulation. 2014; 130(9): 757-767, doi: 10.1161/CIRCULATIONAHA.114.009480, indexed in Pubmed: 25052403.

25. Erdem G, Bakhai A, Taneja AK, et al. Rates and causes of death from non-ST elevation acute coronary syndromes: ten year follow-up of the PRAIS-UK registry. Int J Cardiol. 2013; 168(1): 490-494, doi: 10.1016/j.ijcard.2012.09.160, indexed in Pubmed: 23138011.

26. Prami T, Khanfir H, Deleskog A, et al. Clinical factors associated with initiation of and persistence with ADP receptor-inhibiting oral antiplatelet treatment after acute coronary syndrome: a nationwide cohort study from Finland. BMJ Open. 2016; 6(11): e012604, doi: 10.1136/bmjopen-2016-012604, indexed in Pubmed: 27881527 .

27. Hvelplund A, Galatius S, Madsen M, et al. Significance of the invasive strategy after acute myocardial infarction on prognosis and secondary preventive medication: a nationwide study of 6364 women and 11,915 men. J Invasive Cardiol. 2012; 24(1): 19-24, indexed in Pubmed: 22210585. 